\title{
Theoretical study of the thermal behavior of a new solar collector
}

\author{
Ismail Tabet, Nadir Bellel* \\ Energy Physics Laboratory, University Constantine 1, Algeria
}

\begin{abstract}
In this paper, theoretical study of the thermal behaviour of solar collector with fixed mirror parabolic concentrator, this collector can integrate on the buildings for the heating of water or can used for production cold at low temperature. The collector was considered in the east - west orientation with a slope so that the radiation of sun will be perpendicular to the parabolic surface during day, An explicit expression of the temperature of the heat transfer fluid as a function of the space coordinate in the flow direction and the time dependent solar intensity is developed, Then, the effect of various parameters, such as the inlet heat transfer fluid temperature and the mass flow.
\end{abstract}

Keywords: Solar collector, mini parabolic collector, solar concentrator

\section{Introduction}

Solar thermal is one of the most cost-effective renewable energy technologies and has presented significant global market prospect. Solar concentration is one of these applications. These systems are capable to achieve big out let temperatures at low cost prices. It is possible to use them in thermal power plants, hot water production for heating, and also solar air conditioning. A new collector design, based on evacuated tubular collectors with cylindroids-parabolic concentrator can be utilize solar radiation coming from all directions for any time. Many studies was made on the solar concentrator of different sizes, scale and application type [1]-[2]. Mr. Petrakis [3] makes a comparative study between the theoretical and the experimental of a solar collector with Mini-Parabolic concentrator, He studied the behavior of the thermal efficiency for various values of small concentrating ratios and mass flow rate and it succeeded that As the concentration ratio increases the thermal efficiency increases, with mass flow rate constant, for periods around solar noon. As the mass flow rate increases the thermal efficiency increases around solar noon periods, for the same concentration ratios and also the thermal efficiency increases as a function of mass flow rate but this increase reaches saturation for all concentration Ratios, S. P. Chow [4] treated the optical efficiencies of evacuated tubular collectors with plane, triangular and semi-circular reflectors have been studied experimentally using a calorimetric technique and theoretically using a ray tracing computer program, detailed studies have been made of the dependence of optical efficiency and incident angle modifier as a function of collector tube separation. The results indicated that it is cost-effective to space the collector tubes two or more absorber tube diameters in. Achintya Madduri and all [5] studied Concentrated Evacuated Tubes for Solar-Thermal Energy Generation using Sterling Engine, according to simulations and the experiments prove that it is possible to use concentrators to increase the room temperature of the thermal power extracted starting from a commercial evacuated system from tube and to employ this system modified to increase the effectiveness of the solar-thermals generation of energy, Runsheng Tang and all [6] study the optimal tilt-angles of all-glass evacuated tube solar collectors, he concluded that The use of diffuse flat reflector can significantly improve the energy collection of

\footnotetext{
* Manuscript received July 20, 2015; revised January 19, 2016.

Corresponding author. Tel.: +21366130158; E-mail address: bellelnadir@yahoo.fr.

doi: 10.12720/sgce.5.1.24-28
} 
collectors.

\section{Dynamic Description of the Collector}

The model developed corresponds to direct flow collector Fig. 1. It is not appropriated to vacuum tube with parabolic concentrator used specific fluid in heat pipes to heat the collector inlet fluid by an exchange [7]. The type of solar collector modeled consists of seven vacuum tubes with mini parabolic concentrator. The heat transfer fluid flows in a copper U-tube [8], which is welded to a narrow flat absorber. Thus, the inlet and the outlet are at the same end of the evacuated tube.

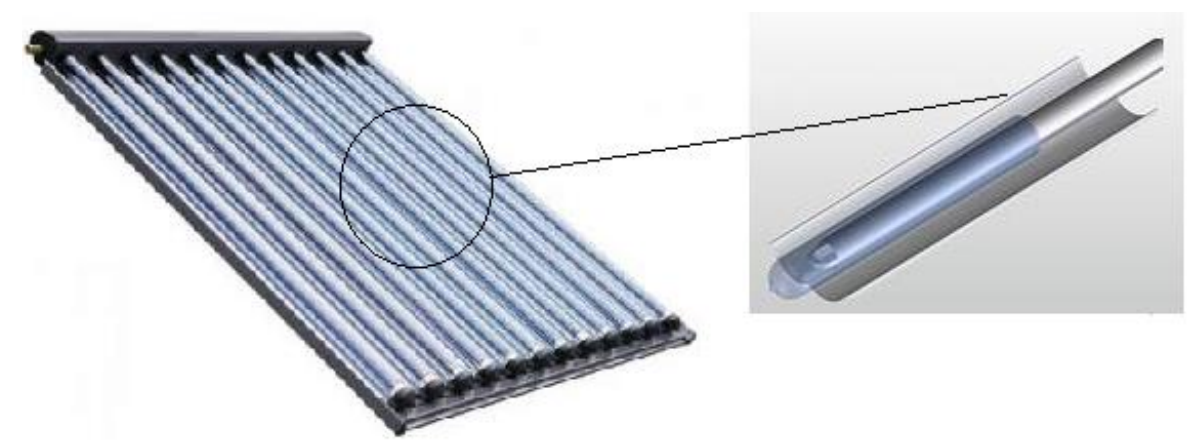

Fig. 1. Solar collector.

\section{Collector Differential Equation System}

The Model consists of four nodes corresponding to the Fluid flow, the receiver, the envelope glass and the transparent cover. It is considered that the temperature of the fluid is a function of $\mathrm{x}$. The fluid is moving in a Single channel with the velocity, along $x$-axis [8].

- Energy balance of transparent cover : $\dot{m}_{c} C_{p c}\left(d T_{d} d t\right)=q_{c}(t)+q_{c-e}^{c}+q_{c-e}^{r}-q_{c-a}^{c}-q_{c-a}^{r}$

- Energy balance of envelope : $\dot{m}_{e} C_{p e}\left(d T_{e} d d \mathrm{t}\right)=q_{e}(t)+q_{c-e}^{c}-q_{c-e}^{r}+q_{e-r}^{c}+q_{e-r}^{r}$

- Energy balance of receiver : $\dot{m}_{r} C_{p e}\left(d T_{r} / d t\right)=q_{r}(t)-q_{e-r}^{c}-q_{e-r}^{r}-q_{r-f}^{c}$

- Energy balance of fluid flow : $\dot{m}_{f} C_{p f}\left(d T_{f} / d t\right)=\dot{m}\left(d t_{f} / d x\right)+q_{r-f}^{c}$

where $q_{c}(t), q_{e}(t), q_{r}(t)$ are, respectively, the solar radiation incident on the cover and absorbed by it, the solar radiation absorbed by the receiver envelope and the beam radiation absorbed by the receiver.

$$
q_{c}(t)=I_{g}(t) \alpha_{c}, \quad q_{r}(t)=I_{g}(t) \tau_{c} \gamma \rho_{m}\left(\alpha_{r} \tau_{e}\right), q_{e}(t)=I_{g}(t) \tau_{c} \gamma \rho_{m} \alpha_{e}
$$

In the practical the variation of the enthalpy of the components of the collector are small we neglect them the terms in $\dot{m} C_{p}(d T / d t)$ can be neglected. We can thus reasonably make the assumption of a quasistationary operation of the collector. This assumption results in to simplify' the equations without however masking the temporary evolution of the phenomena which remain related to solar flow I variable in time. en eliminating $T_{c}, T_{r}, T_{e}$ of the simplified equations thus obtained, it comes [2], [3].

\section{Numerical Procedure}

A numerical calculation, an iterative procedure is adopted to incorporate the effect of the temperature dependence of various heat transfer coefficients. For certain temperature, they are first calculated by using Gauss -Seidel methods. The equations are solved by assuming the heat transfer coefficients constant and then new solutions are used to generate all the heat transfer coefficients again till the values converge.

Calculation was carried out for a place or can about it collect all the solar radiation with the 18 out in east Algeria (Constantine). The characteristics of site and other parameters used for calculation are shown 
in the following Table 1.

Table 1. Input parameter of simulation

\begin{tabular}{|c|c|}
\hline - Parameter & - Value \\
\hline - Zenith angle & - $0^{\circ}$ \\
\hline - $\quad$ Latitude & - $32^{\circ} .17$ \\
\hline - Longitude & - $6^{\circ} .62$ \\
\hline - Collector Type & - 6-trought parabolic collector \\
\hline - Collector inclination & - $30^{\circ}$ \\
\hline - Collector Disposition & - Est. -west \\
\hline - Speed of the Wind & - $1.5 \mathrm{~m} / \mathrm{s}$ \\
\hline - Length of collector & - $1.5 \mathrm{~m}$ \\
\hline - Aperture of channel parabola & - $0.1 \mathrm{~m}$ \\
\hline - Diameter of receiver tube & - $0.022 \mathrm{~m}$ \\
\hline - Diameter envelope tube & - $0.026 \mathrm{~m}$ \\
\hline - Parabola reflectance & - 0.90 \\
\hline - Receiver absorptive & - 0.90 \\
\hline - Receiver emissivity & - 0.80 \\
\hline - envelope absorptance & - 0.023 \\
\hline - envelope transmittance & - 0.9 \\
\hline
\end{tabular}

\section{Results and Discussions}

Fig. 2- Fig. 3 illustrate the effect of the mass flow of the fluid at midday $\mathrm{t}_{\mathrm{m}}(12)$ on the time variations of the local temperature of the fluid and on the efficiency of the collector. We see that the temperature of the fluid decrease with the mass flow increase (Fig. 2). This is explained simply by the fact when the mass flow of the fluid increases, the solar irradiation being maintained constant the quantity of water to heat increase, involving a reduction in its temperature outlet. In the same time since the mass flow of the fluid was increasing, heat is carried much more quickly. This explains the increase in the efficiency of the collector which observed on the Fig. 3. Fig. 4 show the diurnal variation of the thermal efficiency of the collector, we remark for usual mass flow of the fluid. The thermal efficiency of the solar collector reaches values maximum between Ten hour and fourteen hours and that due to solar irradiation, we can say that the Fig. 4 which the collector works with a nearly constant thermal efficiency.

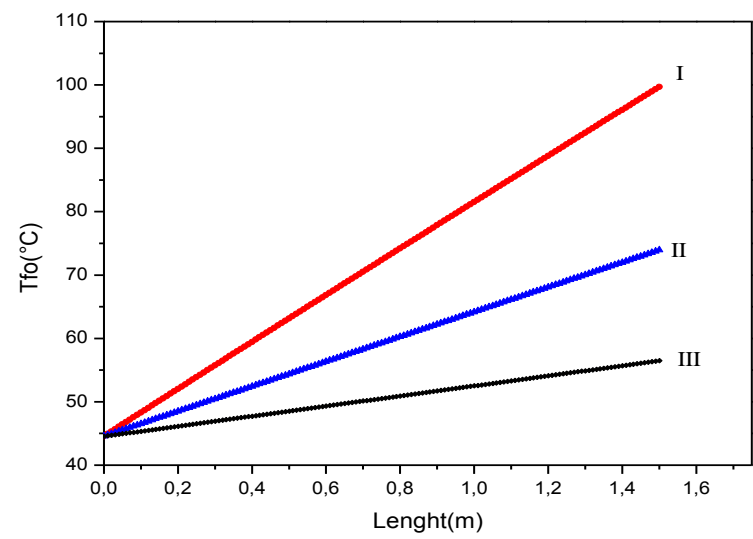

Fig. 2. Effect of mass flow of the fluid on the local temperature of the fluid in the direction of the flow $\left(T_{f i}=T_{a}\right) ; \mathrm{I}-\dot{m}$ $=0.01 \mathrm{~kg} / \mathrm{s}$, II $-\dot{\mathrm{m}}=0.02 \mathrm{~kg} / \mathrm{s}$ III $-\dot{\mathrm{m}}=0.05 \mathrm{~kg} / \mathrm{s}$ ). 
We represented on the figures (5-6) the effect of the inlet temperature $\mathrm{T}_{\mathrm{fi}}$ of the fluid on the local temperature of the fluid $\mathrm{T}_{\mathrm{f}}(\mathrm{x}, \mathrm{tm})$ at the midday $\mathrm{tm}=12 \mathrm{~h}$ on the diurnal variations of the outlet temperature of fluid.

It appears that for a constant mass flow the outlet temperature of the fluid does not believe significantly with the increase of inlet temperature (Fig. 5) because the thermal losses of the collector increase quickly when the inlet temperature of the fluid, so that the increase in the enthalpy of the fluid on the outlet side of the collector is less important than at the inlet.

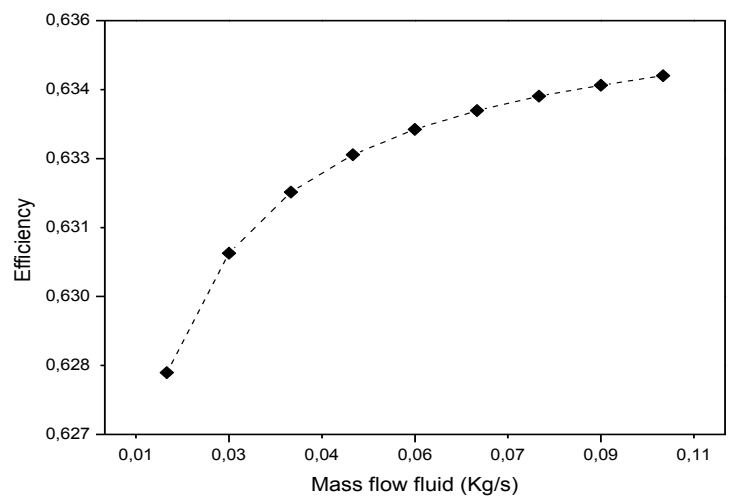

Fig. 3. Effect of the mass flow of the fluid on the efficiency of the collector $\left(T_{f i}=T_{a}\right)$.

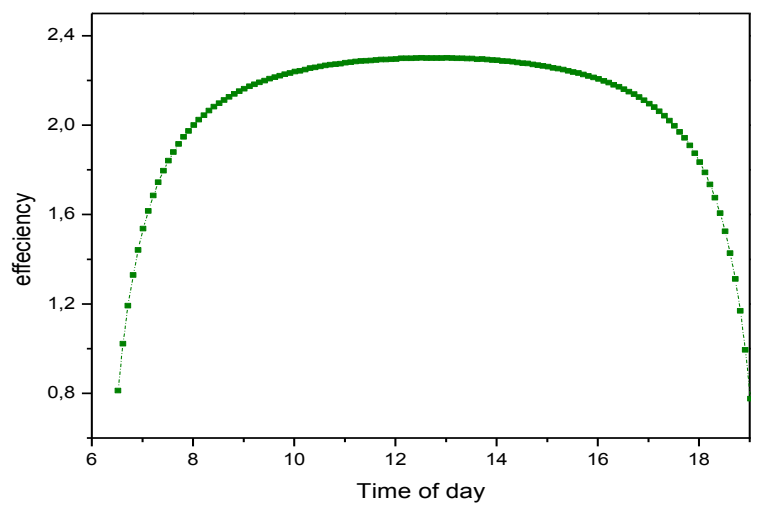

Fig. 4. Diurnal efficiency of collector $\left(\mathrm{T}_{\mathrm{fi}}=\mathrm{T}_{\mathrm{a}}, \dot{m}=0.04 \mathrm{~kg} / \mathrm{s}\right)$.

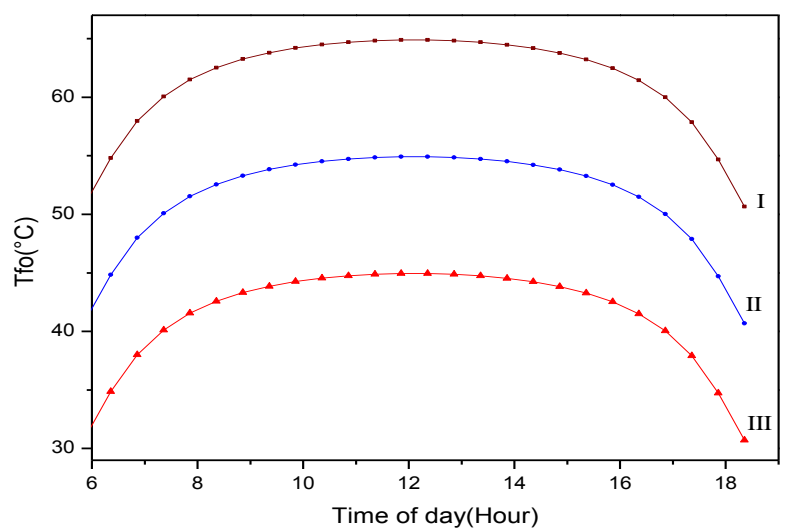

Fig. 5. Effect of the inlet temperature of fluid on the diurnal variation of the outlet temperature of fluid $(\dot{m}=0.01 \mathrm{~kg} / \mathrm{s}$, $\mathrm{I}-\mathrm{T}_{\mathrm{fi}}=50^{\circ} \mathrm{C}, \mathrm{II}-\mathrm{T}_{\mathrm{fi}}=40^{\circ} \mathrm{C}, \mathrm{III}-\mathrm{T}_{\mathrm{fi}}=30^{\circ} \mathrm{C}$ ). 


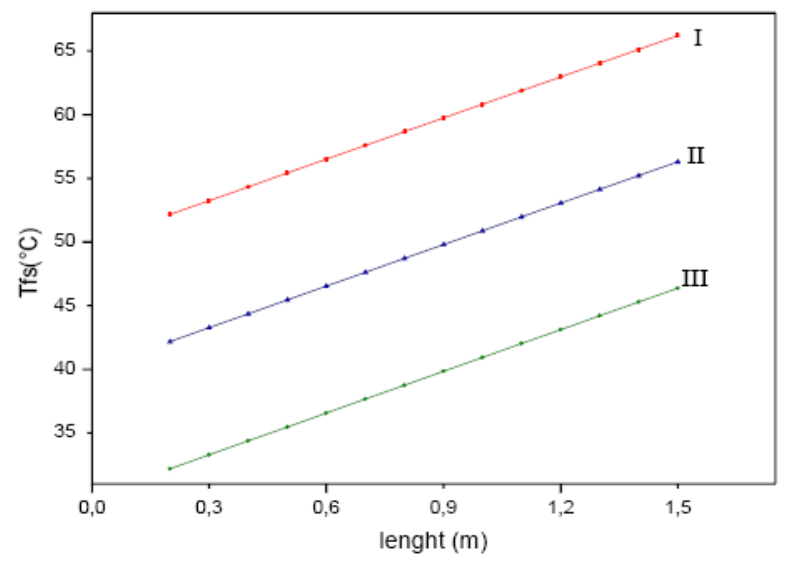

Fig. 6. Effect of inlet temperature of fluid on the local temperature of the fluid in the direction of the flow $(\dot{m}$ $=0.01 \mathrm{~kg} / \mathrm{s}, \mathrm{I}-\mathrm{T}_{\mathrm{fi}}=50^{\circ} \mathrm{C}$, II- $\mathrm{T}_{\mathrm{fi}}=40^{\circ} \mathrm{C}$, III- $\left.\mathrm{T}_{\mathrm{fi}}=30^{\circ} \mathrm{C}\right)$.

\section{Conclusion}

This study will have made it possible to show that the assumption of a quasi-stationary operation, the equation of heat balances of the components of the solar collector with mirrors cylindro-parabolic at the bottom of the collector in ordinary differential equation, which with only governs the thermal behavior of the collector. We showed in this study the influence of some inlet parameter on the thermal efficiency of the collector and the outlet temperature of the collector such as the mass flow of the fluid, the inlet temperature of the fluid.

\section{References}

[1] Tchinda R, Kaptouom E, Njomo D. Study of the c.p.c. collector thermal behavior. Energy Convers. Mgmt., 1998; 39(13): 1395-1406.

[2] Duffy JA, Beckman WA. Solar Energy Thermal Processes. New York: Wiley; 1974: 83.

[3] Pertrakis M, Barakos G, Kaplanis S. Roof integrated mini-parabolic solar collectors. Comparison between simulation and experimental results. The Open Fuels \& Energy Sciences Journal, 2009.

[4] Jean PP, François G, Franck L. Dynamic modelling and elements of validation of solar evacuated tube collectors. In: Proc. of the Ninth International IBPSA Conference, Montréal, Canada, August 15-18, 2005.

[5] Chow SP. Optimisation of evacuated tubular solar collector arrays with diffuse reflectors. Solar Energy, 1984;33: 277-282.

[6] Performance RT, Gao WF, Yu YM, Chen H. Optimal tilt-angles of all-glass evacuated tube solar collectors. Energy, 2009; 34:1387-1395.

[7] Thorsten AS. Automatic control of the 30M We SEGS VI parabolic trough plant. Thesis master of science (Mechanical Engineering), University of Wisconsin-Madison; 2002.

[8] Gang P, Li GQ, Zhou X, Ji J, Su YH. Comparative experimental analysis of the thermal performance of evacuated tube solar water heater systems with and without a Mini-Compound, Parabolic Concentrating (CPC) Reflector (C<1). Energies, 2012; 5(4):911-924. 